\title{
Jump-Start Smoking Cessation
}

\author{
RB Watts MS, Susan S. Hendrick PhD
}

\section{BACKGROUND}

Smoking cessation is at the forefront of behavioral agendas that physicians should have for their patients. Although smoking prevalence has declined overall in recent decades, smoking remains one of the most preventable causes of illness and death. ${ }^{1}$ Smoking is linked to pulmonary diseases (e.g., COPD), cardiovascular disease, several cancers, and multiple other pathologic states as well. The illness burden and the resulting economic burden, estimated at $\$ 200$ billion in healthcare costs and lost productivity, make treatment of smoking a medical priority. ${ }^{1}$

The US Department of Health and Human Services (HHS) has published evidence-based guidelines for the treatment of nicotine dependence. ${ }^{2}$ The logical place for implementation of these guidelines (and briefer versions thereof) is in medical settings that address patients' general illness/wellness, most frequently Internal Medicine or Family Medicine. And even very brief intervention by a physician to target a patient's need for smoking cessation can increase quit rates.

One important fact that patients need to be told is that it is never too late to quit smoking. For example, smoking cessation is useful for virtually any patient with any type of cancer undergoing any treatment. Outcomes of treatment tend to be better, longevity may be increased, and quality of life is higher. ${ }^{3}$ The diagnosis of cancer or serious pulmonary or car-

Cooresponding Author : RB Watts MS Author Contact Information: Rb.watts@ttu.edu DOI: 10.12746/swrccc2014.0206.079 diovascular disease can offer a physician a unique "window of crisis" through which to introduce the idea of reducing and ultimately ceasing to smoke, but the medical-home physician does not want to wait until a severe disease diagnosis. Earlier is better. As noted, HHS offers extensive guidelines for smoking cessation treatment, but sometimes less is more. For example, a Memorial Sloan Kettering study found that cessation counseling and pharmacotherapy were just as effective as both of these combined with a novel behavioral tapering intervention, when both treatment strategies were used with newly diagnosed cancer patients who smoked. ${ }^{4}$ Thus, two modalities were just as effective as three.

Finding the "access point" of a smoker depends on several factors, not limited to but including a respectful and non-blaming physician who can offer help in the form of pharmacotherapy, practical strategies, and encouragement. In the case study that follows, all these elements (plus an appropriate referral) are provided.

\section{CASE}

A 60-year-old male, "John," with a history of chronic obstructive pulmonary disease, hypertension, and tobacco abuse (smoking) arrived in clinic for a routine follow-up appointment. In previous visits, the patient would quickly deny any desire to quit smoking and would try to change the subject. However, John's COPD symptoms are worsening and his smoking behavior is considered to be a primary contributing factor. How could John's physician address smoking cessation in the clinic appointment? 


\section{Discussion}

The following conversation between John and his physician will demonstrate a typical and appropriate brief smoking cessation intervention. This conversation begins after discussing John's worsening COPD symptoms:

Physician: I'm told that you are still smoking. I know we've talked about smoking in the past, and you haven't been interested in quitting, but I have to say that I am starting to see signs that your COPD is getting worse. Unfortunately, continuing to smoke will most likely cause further problems and make treatment very difficult. I must strongly advise you again to think about quitting.

John: Yeah, I know. I've actually been trying to cut back. I was smoking two packs a day, but I am now down to around one.

P: That's great! Cutting out any amount of cigarettes is a move in the right direction. It sounds like you've been taking the idea of quitting more seriously. What reasons do you have to quit smoking?

J: Well, I have also noticed my breathing becoming more difficult, and I have been coughing a lot more which has been scaring me a bit. I just had a new granddaughter and I really want to make sure I can be around in her life as much as possible.

P: I certainly want that for you as well. Quitting smoking is a very tough thing to do, and if you'd like, we can talk about some options we have available to help you along.

J: Sure, I could really use some help.

At this point, John and his physician discuss options regarding nicotine replacement therapies and smoking cessation medications. Patients will vary in regards to which medications or replacement therapies are appropriate.

J: OK, I think I'll try out the nicotine patch, though I don't think I want to try Chantix.

P: Great, sounds like we have a plan. Also, if you feel like you could use a little extra help before our next visit, you can call 1-800-QUIT-NOW. They can provide extra help and resources as you try to quit. It's important to take specific steps to try to keep yourself from automatically grabbing cigarettes through the day, and the people at that number can help you.

J: OK, l'll keep that in mind.

P: Excellent, I'm so happy that you are taking these steps. l'd like to see you in three weeks. Then, we can check in and see how things are going. If you're still having trouble, we can see what other things we can do to help you quit.

In this brief intervention, the physician was able to quickly address John's smoking behaviors. First, as is important with every tobacco- using patient at every visit, the physician assessed John's current smoking behaviors. Following this, the physician then advised John to quit smoking. Though John had refused to consider smoking cessation in the past, it became apparent in this visit that he was beginning to feel motivated to quit. Helping a patient quit smoking can sometimes be a long-term process spanning multiple clinic visits. John's physician noticed the sudden shift in motivation and capitalized on this and provided assistance in recommending specific medical intervention. Additionally, the physician provided extra resources outside the clinic, in this case a national hotline. If there are other resources available to you, such as access to counselors trained in behavioral smoking cessation interventions or support groups in the local area, then integrating these resources can help increase the likelihood that the patient will succeed in ceasing tobacco use. Finally, the physician made sure to arrange for a follow-up with the patient to check in about smoking. This allows the physician to monitor this critical health behavior, and it can provide the patient with a greater sense of support through this very challenging experience.

Smoking cessation is a difficult process for 
both the patient and their healthcare providers. However, brief interventions at each visit, and providing assistance once the patient appears motivated to quit, can greatly increase the chances of improving the health of many patients.

Author Affiliation: RB Watts is a graduate student in psychology at Texas Tech University in Lubbock, TX. Susan $\mathrm{S}$. Hendrick is a professor in psychology at TTU in Lubbock, TX.

Received: 01/14/2014

Accepted: 04/01/2014

Reviewers: Cynthia Jumper MD

Published electronically: 04/15/2014

Conflict of Interest Disclosures: None

\section{REFERENCES}

1. Fiore MC, Baker TB. Treating smokers in the health care setting. NEJM 2011; 365: 1222-1231.

2. Fiore MC, Jaen CR, Baker TB, et al. Treating tobacco use and dependence: 2008 update. Rockville, MD: Dept. of HHS, US Pub Health Serv, 2008.

3. Bath C. Patients with cancer need to know that it is never too late to quit smoking. ASCO Post; Mar 15, 2013: 120-121.

4. Ostroff J, Burkhalter J, Cinciripini P, et al. Randomized trial of a presurgical, scheduled reduced smoking intervention for patients newly diagnosed with cancer. Poster presented at 2013 APOS Annual Conf, Feb 15, 2013. As cited in Bales K. Tobacco cessation needed in routine cancer care. ASCO Post, Mar 15, 2013: 35 . 